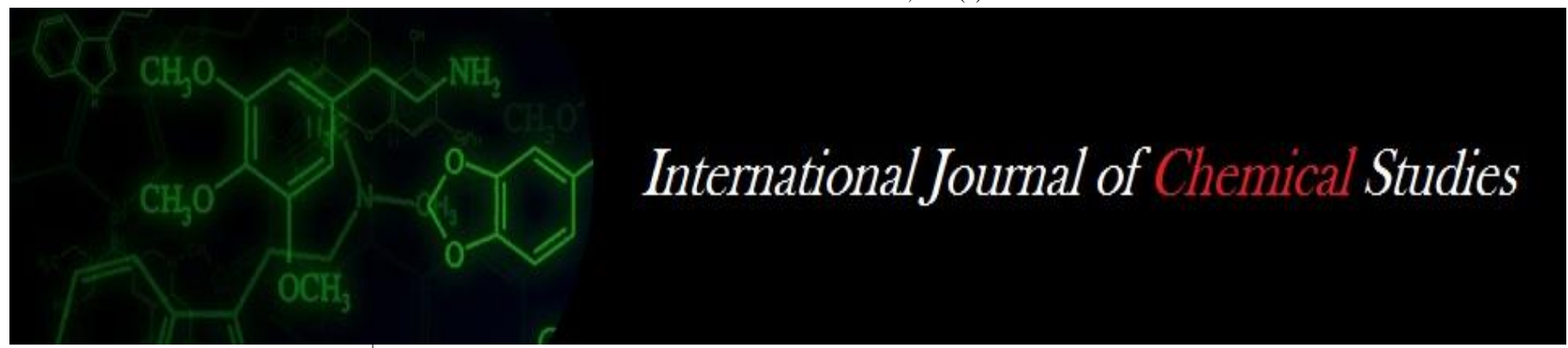

P-ISSN: 2349-8528

E-ISSN: 2321-4902

www.chemijournal.com

IJCS 2020; SP-8(4): 417-420

(C) 2020 IJCS

Received: 25-05-2020

Accepted: 26-06-2020

Manoj Kumar Awasthi Chief Scientist, AICRP on Irrigation Water Management, Department of Soil and Water Engineering, College of Agricultural Engineering, JNKVV, Jabalpur, Madhya Pradesh, India

Deepak Patle

Ph.D. Scholar, Department of Soil and Water Engineering, College of Agricultural Engineering, JNKVV, Jabalpur, 482004, Madhya Pradesh, India

Corresponding Author:

Manoj Kumar Awasthi Chief Scientist, AICRP on

Irrigation Water Management, Department of Soil and Water

Engineering, College of Agricultural Engineering, JNKVV, Jabalpur, Madhya Pradesh, India

\section{Trend analysis of ground water recharge in Tikamgarh district of Bundelkhand using geospatial technology}

\author{
Manoj Kumar Awasthi and Deepak Patle
}

DOI: https://doi.org/10.22271/chemi.2020.v8.i4g.10181

\begin{abstract}
Efficacy of soil and water conservation works are generally adjudged on the basis of changes in water level and reduction in soil erosion. A study of 20 years was conducted in Tikamgarh district of Bundelkhand region in which groundwater recharge was quantified and compared for pre project (Phase1) and post project (Phase-2) periods on the basis of the average values. The trends in rate of change in groundwater recharge during pre and post phase were also worked out. Records of 100 Permanent Observation Wells were used to identify the trend of declining / rising water levels results in rising trend in about two thirds areas. Non parametric Mann-Kendall test yields rising trend in Phase- 2 in 65 percent area and magnitude of Sen's slope revealed higher positive magnitude upto 0.025 .
\end{abstract}

Keywords: Ground water recharge, mann-kendall test, sen's slope estimator, permanent observation wells, water level fluctuation method, Bundelkhand

\section{Introduction}

Quantified Ground water recharge has been used as indicator to assess the efficiency of works on soil water conservation. Mostly, the average seasonal ground water recharge as obtained in pre and post project periods are used to compare for this. The very purpose of all soil and water conservation works is to arrest soil and declining trend of water table, therefore, the trend analysis may provide better view of impact of these structures. Because it may be quite possible to have lesser quantity of ground water recharge in project phase but with indicated trend.

An effort has been carried out in this study to see the situation with both the angles and show the difference there on. In Tikamgarh district $\left(5048 \mathrm{~km}^{2}\right)$ where lot of Soil and Water Conservation work were done under Bundelkhand Special Package Programme since 2007. The water level data (1997-2016) of 100 permanent observation wells (POWs) were analysed. The whole of study period divided in two phases, Phase-1 (1997-2006) as pre project period and Phase-2 as project period.

\section{Materials and Methods}

Study Area

Tikamgarh district is situated in the Northern part of Madhya Pradesh on the Bundelkhand Plateau between Jamuni, (a tributary of Betwa) and Dhasan River. It extends between $24^{\circ} 26^{\prime}$ and $25^{\circ} 34^{\prime} \mathrm{N}$ latitudes and $78^{\circ} 26^{\prime}$ and $79^{\circ} 21^{\prime}$ E longitudes. The maximum length of the district is about $119 \mathrm{~km}$ from North to South and width is about $80 \mathrm{~km}$. The major part of the study area is comprised of granite rocks and soils are classified as black humus granitic and yellowish grey colour with kankar soils. The entire district comes under Betwa sub basin of Ganga basin. The groundwater in the area generally occurs under water table conditions.

\section{Data Use and Analysis}

The groundwater level data of 100 Permanent Observation Wells (POWs) tapping unconfined aquifer were collected for 20 years (1997-2016) from the State government agencies. Using subsheets of toposheet 54K, 54L, 54O and 54P, the block boundaries are digitized in GIS platform with Arc map 10.3 and on shape file of thus prepared district map the location of POWs are marked using their lat-long coordinates. 
Thiessen polygons were drawn to demarcate the area of influence of the each well (common polygon) because it defines an area of influence around its sample point, such that any location inside the polygon is closer to that point than any of the other sample points. Further, the administrative units have been demarcated in each polygon and the recharge has been estimated through the Water Table Fluctuation method, which is the one of the most significant method for estimation of groundwater recharge. The change in storage will be computed by multiplying water level fluctuation between pre and post monsoon seasons with the area of assessment and specific yield (GEC, 1997) ${ }^{[3]}$. For statistical analysis, "Auto_MK_Sen.exe" program was used which employ Mann-Kendall test for the determination of trend and the Sen's Slope for finding slope magnitude.

The use of the Mann-Kendall (MK) test (Mann 1945, Kendall 1975 , Gilbert 1987) ${ }^{[6,5,4]}$ is to statistically measure if there is a monotonic rising or downward trend of the variable of interest over time. An upward trend means that the variable steadily increases through time and vice versa, but the trend can or cannot be linear. This statistics depicts that the number of positive differences minus the number of negative differences. If is a positive number, observations acquired later in time tend to be larger than observations made earlier. If is a negative number, then observations acquired later in time tend to be lesser than observations made earlier.

A functional relationship has been established between variables using linear regression analysis and non-parametric method Mann-Kendall test in order to determine a linear trend of rainfall for the study area (Nema and Awasthi, 2016) ${ }^{[7]}$.

The magnitude of trend in a hydrologic time series is determined using non-parametric method known as Sen's estimator (Sen, 1968). This method assumes a linear trend in the time series. In this method, the slopes (Ti) of all data sets are calculated first by

$$
Q=\frac{Y^{\prime}{ }_{i}-Y_{i}}{i^{\prime}-i}
$$

$\mathrm{Q}$ is a slope estimate.

$\mathrm{Yi}$ ' are Yi the values at times i' and i, where $i^{\prime}$ is more than $i$, $N^{\prime}$ is all data sets for which i' is bigger than i. Sen's estimator of slope is the median of the $\mathrm{N}^{\prime}$ values of $\mathrm{Q}$. The same procedure is monitored whether there are one or multiple observations per time period. A positive value of $\mathrm{Q}$ shows an upward trend and a negative value shows a downward trend in the time series.

\section{Results and Discussion \\ Impact assessment based on average ground water recharge values}

Pre and post monsoon water level data of each of 100 POWs were analysed and the difference of these two on multiplications to well influence area as per Thiessen Polygon and specific yields of aquifer yields quantity of groundwater recharge. Its spatial distribution for Phase-1 and Phase- 2 is presented in Fig. 1 and class frequency distribution is presented in Table 1. Figure depicts overall decrease in ground water recharge from Phase- 1 to Phase-2. There is $3966 \mathrm{~km}^{2}(78.51 \%)$ area comes under ground water recharge class $0.081-0.120 \mathrm{~m}$ in Phase- 1 and in comparison to this only $1374 \mathrm{~km}^{2}(47.15 \%)$ area comes under the same class in Phase-2. For other classes also Phase-2 depicts lesser quantum of ground water recharge. The difference between average ground water recharges of both the phases in each of influence area of all POWs are shown in Fig. 2, where it shows that about two-third areas has less than $30 \%$ difference in magnitude of ground water recharge. Well distribution of difference classes of ground water recharge in the Fig.2 shows non dominance of localized recharge.
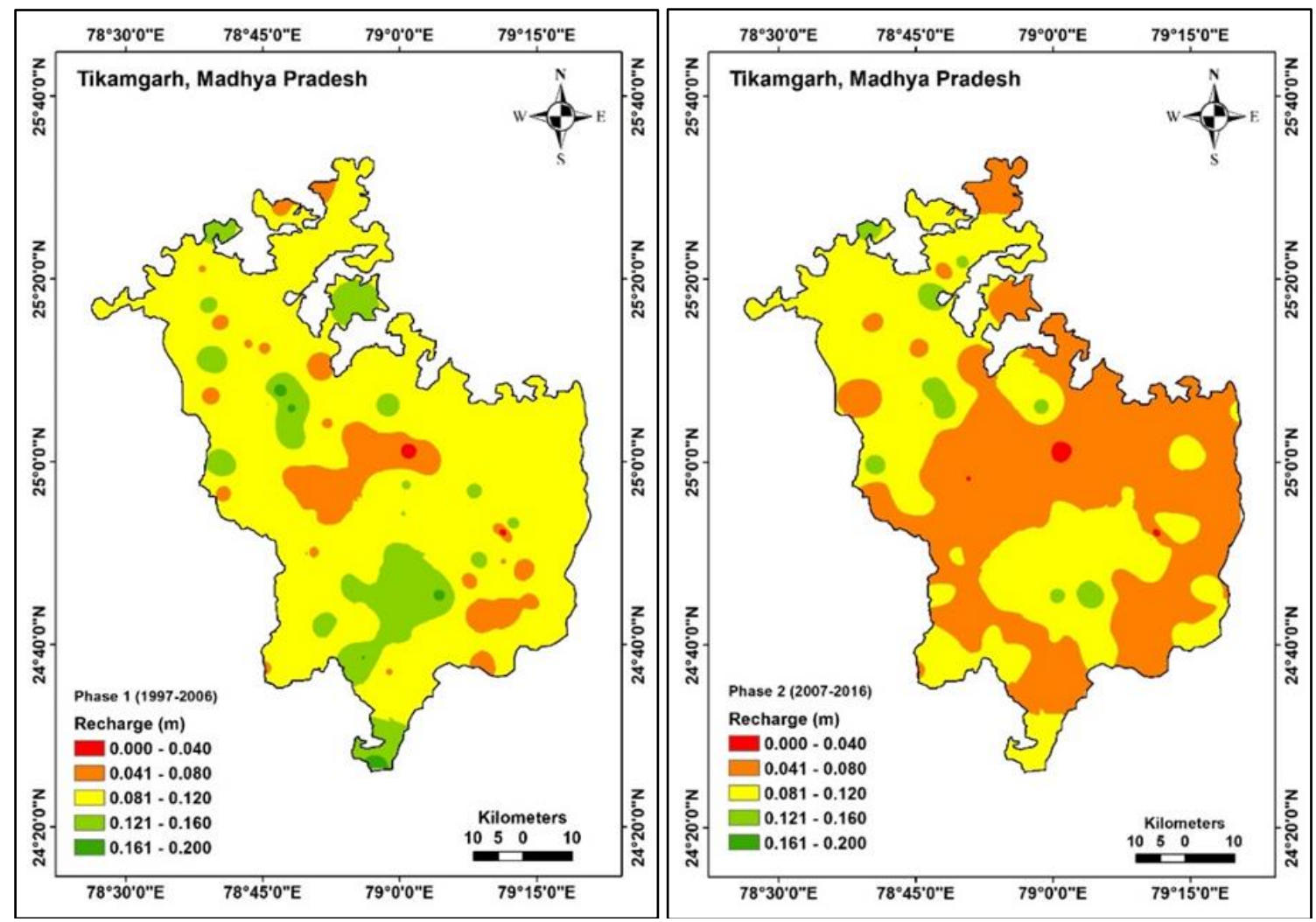

Fig 1: Spatial distribution of Recharge (m) for Phase-1 and Phase-2

The above discussion is inconclusive regarding change in pattern of ground water recharge from Phase-1 to Phase- 2 . 
Table 1: Recharge classes with frequency distribution for Phase-1 and Phase-2

\begin{tabular}{|c|c|c|c|c|c|}
\hline \multirow[b]{2}{*}{ Class } & \multirow[b]{2}{*}{ Recharge (m) } & \multicolumn{2}{|c|}{ Phase-1 (1997-2006) } & \multicolumn{2}{|c|}{ Phase-2 (2007-2016) } \\
\hline & & $\operatorname{Area}\left(\mathrm{km}^{2}\right)$ & $\%$ & Area $\left(\mathrm{km}^{2}\right)$ & $\%$ \\
\hline 1 & $0.000-0.040$ & 8 & 0.16 & 14 & 0.28 \\
\hline 2 & $0.041-0.080$ & 456 & 9.03 & 2541 & 50.34 \\
\hline 3 & $0.081-0.120$ & 3966 & 78.57 & 2374 & 47.03 \\
\hline 4 & $0.121-0.160$ & 598 & 11.85 & 119 & 2.36 \\
\hline 5 & $0.161-0.200$ & 20 & 0.40 & 0 & 0.00 \\
\hline
\end{tabular}

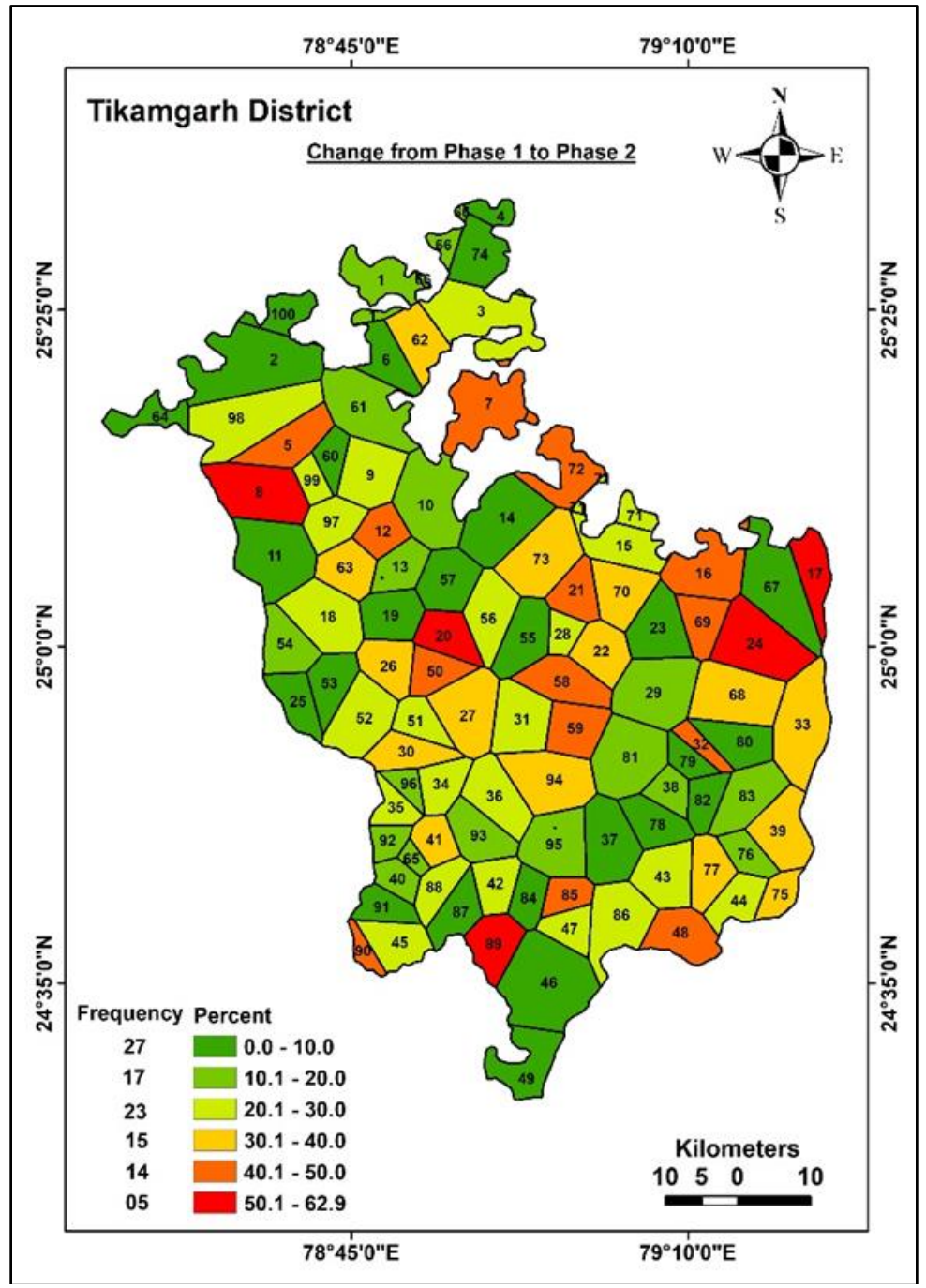

Fig. 2. Ground water recharge change from Phase-1 and Phase-2

Impact assessment based on trend in ground water recharge values

Ground water recharge values of 20 years obtained through 100 POWs for Phase- 1 and Phase- 2 are analysed for time series using Mann-Kendall test and Sen's slope. Ground water Recharge trends obtained from Mann-Kendall test are grouped into Z- classes and depicted in Fig.3. During Phase-1, more negatives are noticed than those obtained in Phase-2. The frequency of 13 was obtained during Phase-1 for Z-class $(-3.00-2.00)$ in comparison to only 01 in Phase2. Similarly for Z-class $(-1.99--1.00)$ there were 32 entries in Phase- 1 as against only 10 in Phase- 2 . For positive trends, it was 10 and 8 wells only in Phase-1 against 25 and 29 wells respectively for class $(0.01-1.00)$ and $(1.01-2.00)$ in Phase-2. Patle \& Awasthi
(2019) [8] in the water level fluctuation studies have found the decrease of declined rate of water level in Phase- 2 in comparison to Phase-1.

Hence, trend analysis clearly indicates positive changes are coming up from Phase- 1 to Phase-2. The magnitude of $\mathrm{Z}$ is seen though Sen's slope and for each of the well the magnitudes are presented in Fig. 4 and it may be seen here that higher positive magnitudes are lying in Phase-2. The Sen's slope estimator which is the measure of the magnitude of recharge was found negative in most of the wells in Phase-1 but found positive in Phase-2 in most of the wells. Out of the 100 POW, 77 wells show negatives and 23 wells show positive magnitude in Phase-1 while in Phase-2, there are 65 wells have positive magnitude and 35 wells have the negative magnitude. 

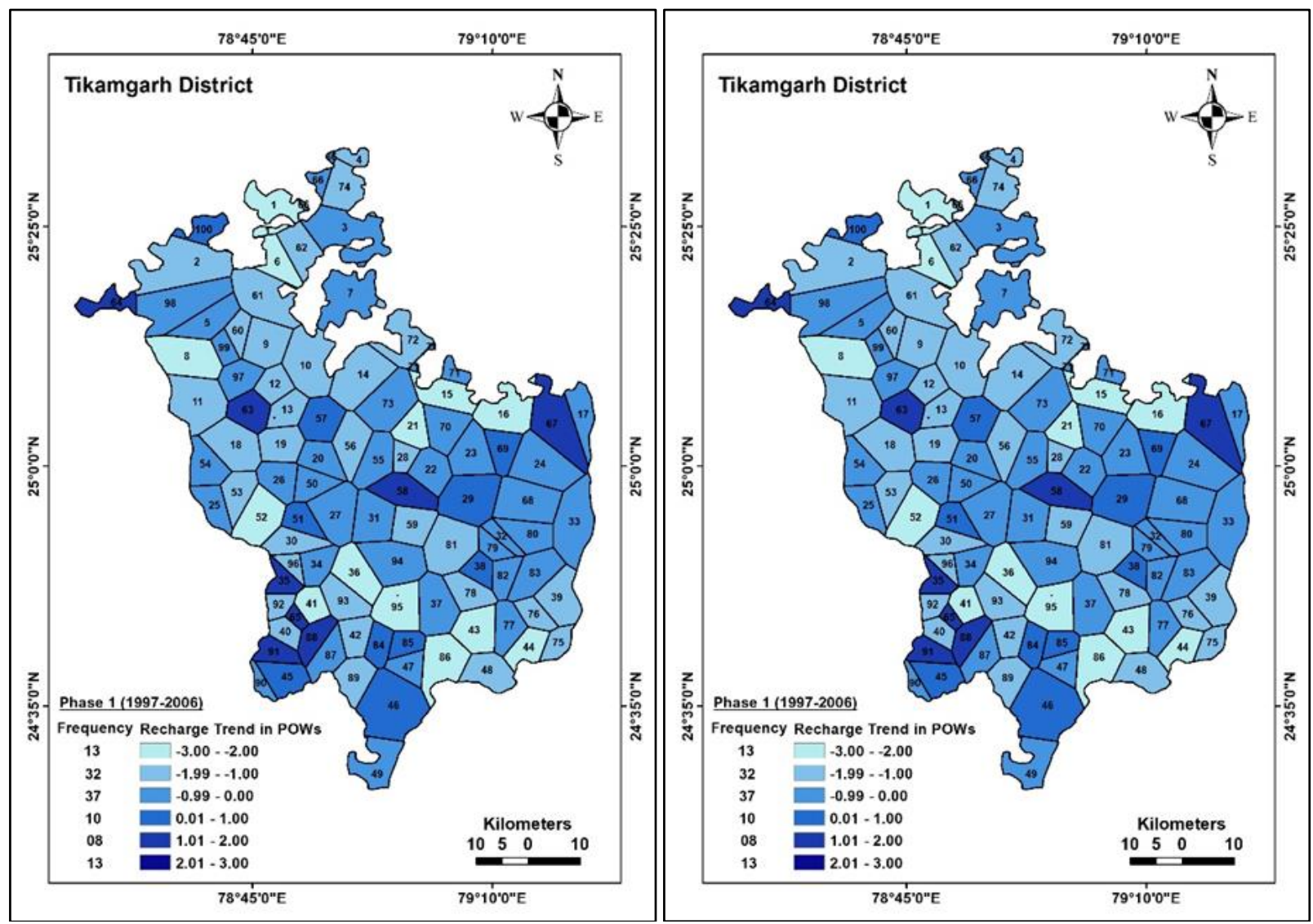

Fig 3: Ground water recharge trend (Z-value) in Phase-1 and Phase-2

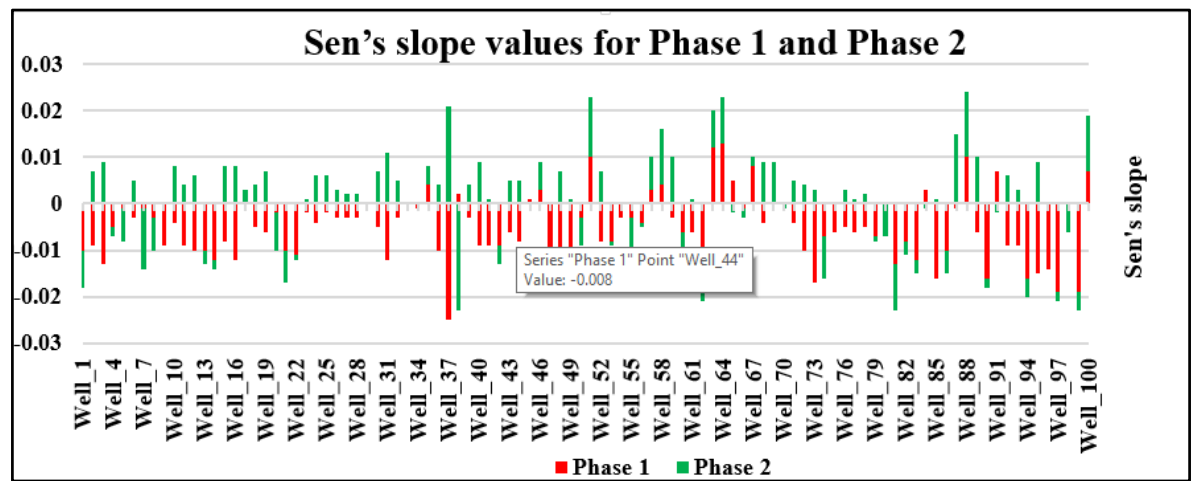

Fig.4. Ground water recharge magnitude (Sen's slope value) in Phase-1 and Phase-2

\section{Conclusion}

Study conducted in Tikamgarh district of Bundelkhand to see the impact of Soil Water Conservation work on ground water recharge through analysis of water level records of 100 permanent observation wells for the period 1997-2016, reveals that the impact of Soil Water Conservation work may be well represented by the trend analysis of ground water recharge. It is a better predictor than average ground water recharge presenting pre and post of project periods. As more than two-third POWs show positive trend regarding ground water recharge in post phase period while it was inconclusive when comparing average ground water recharge of pre and post project periods

\section{Acknowledgement}

Authors thankfully acknowledge the Dean, College of Agricultural Engineering, JNKVV, Jabalpur for providing necessary facilities. Additionally appreciative to IWMP \& MGNREGA, Tikamgarh and the State Water Data Centre, Bhopal for providing required data.

\section{References}

1. CGWB. Artificial ground water recharge with a special reference to India, 1994. http://cgwb.gov.in/documents/ArtificialRecharge-Guide.pdf
2. District Ground Water Information Booklet. Ministry of Water Resources. Central Ground Water Board. North Central Region, Bhopal, Madhya Pradesh. Government of India, 2013. http://cgwb.gov.in/District_Profile/MP/Tikamgarh.pdf

3. GEC. Report of the Ground Water Resource Estimation Committee. Ministry of Water Resources, Government of India, New Delhi, 1997.

4. Gilbert RO. Statistical Methods for Environmental Pollution Monitoring, Wiley, NY, 1987.

5. Kendall MG. Rank Correlation Methods, 4th edition, Charles Griffin, London, 1975.

6. Mann HB. Non-parametric tests against trend. Econometrica. 1945; 13:163-171.

7. Nema Sourabh, Awasthi MK, Nema RK. Trend Analysis of Annual and Seasonal Rainfall in Tawa command Area. International Journal of Environment, Agriculture and Biotechnology. 2016; 1(4):952-957.

8. Patle Deepak, Awasthi MK. Past Two Decadal Groundwater Level Study in Tikamgarh District of Bundelkhand. Journal of the Geological Society of India. 2019; 94(4):416-418.

9. Toposheets of Tikamgarh district, Madhya Pradesh. Survey of India. Nakshe Portal. http://www.soinakshe.uk.gov.in/searchbygeodata.aspx 